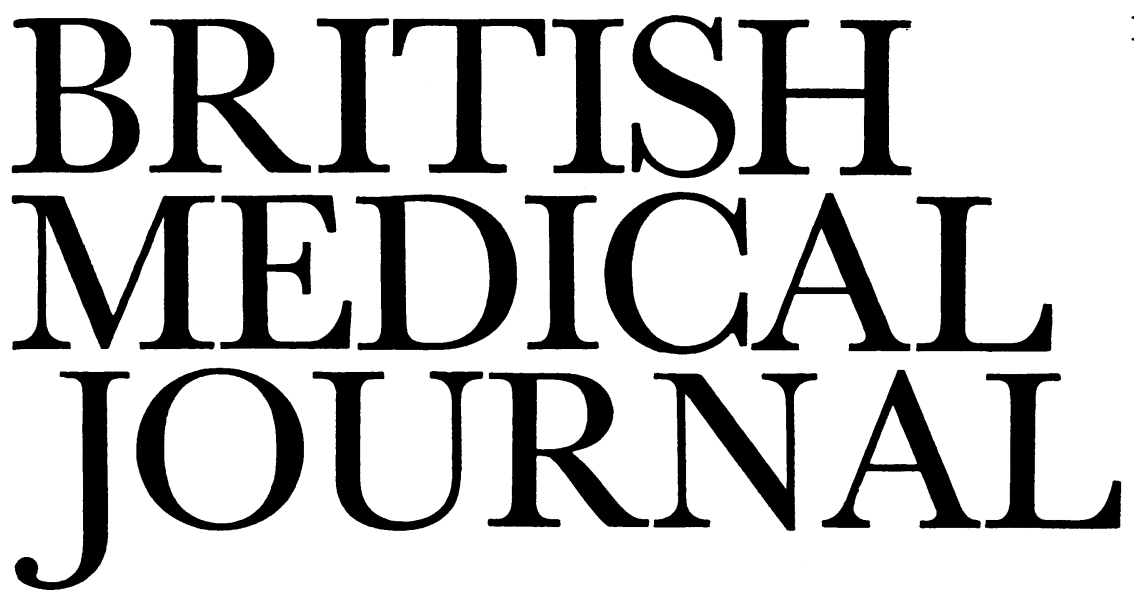

LONDON, SATURDAY 27 FEBRUARY 1982

\title{
Exercise testing in the diagnosis of ischaemic heart disease
}

Interest in exercise testing for the diagnosis and management of coronary artery disease has swung back and forth over the past 50 years. The treadmill and bicycle ergometer provide means of maximally stressing patients, and with efficient resuscitation procedures this may be done safely. The increasing use of coronary angiography has, for the first time, provided a yardstick against which the results can be assessed, and the advantages and limitations of both tests are now beginning to be realised. ${ }^{2}$ The shortcomings of stress testing soon became clear in terms both of diagnosis and of providing any quantitative assessment; on the other hand, coronary angiography was found to provide inadequate physiological information.

In the diagnosis of coronary artery disease most interest has been concentrated on ST segment abnormalities, and in particular planar ST segment depression; but stress testing provides much more information than simply this for physicians treating patients with chest pain. It provides a means of directly observing the patient's response to exercise and the amount of work he can do together with the symptoms associated with exercise, which may not be limited to chest pain. Recording any arrhythmias that may develop during exercise may also be important.

Comparisons between the ST segment response and coronary arteriography have led to considerable controversy. ${ }^{13}$ Several studies have shown that planar ST segment depression recorded on exercise is a sensitive indicator of coronary artery disease, but some others have not confirmed this finding. These contrasts are likely to be due to differences in the population under study. ${ }^{4}$ Most studies of angina pectoris are performed in patients undergoing cardiac catheterisation, and the prevalence of ischaemic heart disease in such a population, who tend to have classic angina pectoris, will be high. In these circumstances the sensitivity and specificity of exercise testing will be excellent. In patients who do not have chest pain, however, the results of exercise testing are less good-as might be expected since it is axiomatic that the predictive value of any diagnostic test diminishes as the prevalence of the disease declines in the population. ${ }^{56}$ Redwood and colleagues, ${ }^{7}$ for example, analysed the outcome of stress tests in populations with high and low prevalences of coronary disease, showing that it is theoretically possible to have more false-positive diagnoses than true positive diagnoses in people in whom the prevalence of coronary disease is low. In practice the sensitivity and specificity of stress testing in asymptomatic people with relatively low coronary prevalence are not known; these probably cannot be assumed to be the same as those in symptomatic patients. ${ }^{8}$

Few workers would disagree with the conclusion that in general a finding of planar ST segment depression during anginal chest pain provoked by exercise is strong evidence of myocardial ischaemia, provided that other causes of ST segment depression (such as digitalis, hypertension, and hypertrophic obstructive cardiomyopathy) are excluded. Studies are still in progress on how close a correlation is possible between the extent of disease found at coronary angiography and the electrocardiographic and haemodynamic response, but the use of multiple leads ${ }^{910}$ and heart rate response ${ }^{11}$ has yielded promising preliminary results.

Many of the controversial aspects of the use of stress testing in coronary artery disease stem as much from the gold standard against which it is compared as from intrinsic difficulties in the stress test itself. Exercise testing is a physiological investigation that defines myocardial ischaemia, and coronary artery disease may be present without the patient ever developing myocardial ischaemia. In both dogs and man stress-induced angina usually implies a $70 \%$ narrowing of a major coronary artery. Nevertheless, the presence or absence of collateral flow and the presence of variable superimposed factors, such as coronary spasm or platelet aggregation, are all-important factors in the development of myocardial ischaemia that will not be evident on simple inspection of a coronary angiogram. Clearly, therefore, the exercise test should be considered as complementary and not as a substitute for the history, physical examination, and coronary arteriogram in the diagnosis and management of patients presenting with chest pain.

With proper selection of patients the hazards of exercise testing are small. In a study from 73 medical centres based on 170000 exercise tests, the mortality was about $0.01 \%$ and the morbidity requiring admission to hospital $0 \cdot 2 \% \cdot{ }^{12}$ All the 16 deaths reported occurred within one week of the exercise test and eight were immediate. Mortality was apparently unrelated to the type or severity of the exercise performed. Ventricular fibrillation occurred in one in 4000 tests. In a more recent study of 15000 maximal exercise tests performed over 10 years there were no deaths. ${ }^{13}$ Two patients had cardiac arrests after exercise without subsequent myocardial infarction. Such results, however, can be obtained only if a careful protocol is 
followed: full resuscitation equipment must be available; the electrocardiograph must be continuously monitored; and a doctor must be present throughout the test and for at least 10 minutes after the end of exercise.

K M Fox

Consultant Cardiologist,

National Heart Hospital,

London W 1

${ }^{1}$ Borer JS, Brensike JF, Redwood DR, et al. Limitations of the electrocardiographic response to exercise in predicting coronary-artery disease. N Engl f Med $1975 ; 293: 367-71$.

2 Selwyn AP, Steiner R, Kivisaari A, Fox K, Forse G. Krypton-81m in the physiologic assessment of coronary arterial stenosis in man. Am $\mathcal{f}$ Cardiol $1979 ; 43: 547-53$.

${ }^{3}$ McHenry PL, Phillips JF, Knoebel SB. Correlation of computer-quantitated treadmill exercise electrocardiogram with arteriographic location of coronary artery disease. Am $\mathcal{F}$ Cardiol $1972 ; 30: 747-52$

4 Detry J-MR, Kapita BM, Cosyns J, Sottiaux B, Brasseur LA, Rousseau MF. Diagnostic value of history and maximal exercise electrocardiography in men and women suspected of coronary heart disease. Circulation $1977 ; 56: 756-61$.

${ }^{5}$ Jelliffe RW. Quantitative aspects of clinical judgment. $A m \mathcal{F}$ Med 1973;55: 431-3.

6 Diamond GA, Forrester JS. Analysis of probability as an aid in the clinical diagnosis of coronary-artery disease. $N$ Engl f Med 1979;300:1350-8.

${ }^{7}$ Redwood DR, Borer JS, Epstein SE. Whither the ST segment during exercise ? Circulation 1976;54:703-6.

${ }^{8} \mathrm{McHenry}$ PL. The actual prevalence of false positive ST-segment responses to exercise in clinically normal subjects remains undefined. Circulation 1977;55:683-5.

${ }^{9}$ Fox KM, Selwyn AP, Oakley D, Shillingford JP. Relation between the precordial projection of $S-T$ segment changes after exercise and coronary angiographic findings. Am $\mathcal{F}$ Cardiol 1979;44:1068-75.

10 Baron DW, Poole-Wilson PA, Rickards AF. Maximal 12-lead exercise testing for prediction of severity of coronary artery disease. Euro $7 \mathrm{Cardiol}$ $1980 ; 11: 259-67$.

11 Flamin MS, Mary DASG, Smith DR, Linden RJ. Prediction of severity of coronary artery disease using slope of submaximal ST segment/heart rate relationship. Cardiovasc Res 1980;14:681-91.

12 Rochmis P, Blackburn H. Exercise tests. A survey of procedures, safety and litigation experience in approximately 170000 tests. $\mathcal{F} A M A 1971 ; 217$ : 1061-6.

${ }^{13}$ Bruce RA. Progress in exercise cardiology. In: Yu PN, Goodwin JF, eds. Progress in cardiology. Vol 3. Philadelphia: Lea and Febiger, 1974:11372.

\section{The legal threat to medicine}

"The first purpose of medicine," as Mr Justice Devlin" 2 explained to the jury at the trial of Dr Bodkin Adams, "is the restoration of health. If this can no longer be achieved," he continued, "there is still much for a doctor to do, and he is entitled to do all that is proper and necessary to relieve pain and suffering, even if the measures he takes may incidentally shorten life." Dr Bodkin Adams had given large doses of morphine to a number of elderly women patients. He was convicted of several offences against various regulations concerned with dangerous drugs, cremation, and other matters associated with the deaths; but the jury found him not guilty of homicide. The case attracted considerable attention at the time and was regarded as establishing the legality of certain treatments that might incidentally shorten life. The possibility that such a pronouncement could be reversed by a higher court was regarded as academic, as the medical profession and the public considered that such a reversal would have the most serious consequences for the care of patients suffering from terminal illnesses.

Unfortunately, this is no longer the case. The Director of Public Prosecutions, ${ }^{3}$ who is required "to give advice whether on application by or on his own initiative to Government departments, clerks to justices, chief officers of police, and such other persons as he may think right in any criminal matter which appears to him to be of importance or difficulty or which for any other reason appears to him to require his intervention by way of advice and any such advice may be given at his discretion either orally or in writing," has pronounced" inter alia "that doctors who deliberately speed death could face the prospect of life imprisonment." This can mean only that he intends to challenge Lord Devlin's direction in the Bodkin Adams case. There are several important issues arising out of his pronouncement and the way in which it was made.

The first is that some unlucky doctor may shortly find himself charged with murder for giving treatment to a dying patient that incidentally hastens death. The second is that patients may find doctors more concerned about the legal indications for treatment of terminal illness than the medical motivation for treatment. Finally, we should note that the person to whom the Director of Public Prosecutions thought it right to give this advice was a reporter from the Daily Telegraph, to whom he granted an exclusive interview.

The newspaper report includes an apologia for having prosecuted Dr Arthur. ("If the prosecution had known in advance of the expert evidence to be produced by the defence it would have changed the whole course of the trial. We might not have charged murder in the first place.") It also reports the Director of Public Prosecutions's proposal that a new offence should be created specifically to deal with doctors charged with such offences. It reports his view that the law of abortion is not clear, and it contains a specific "warning" to doctors that he will "certainly have to consider whether the public interest requires a prosecution" in cases where a doctor has deliberately ended the life of a baby.

With regard to the first point, the Director of Public Prosecutions does not appear to have considered that it is the fault of our legal system that this happened. Any legal system which discourages the expert witnesses from talking to each other is bound to lead to such a situation. As for a new offence for doctors "speeding the death" of their patients, we cannot seriously accept that a doctor who eases the pain and suffering of a terminal illness should be guilty of any crime. On the Abortion Act, the Lane Committee presented three volumes of a report to Parliament in 1975 concluding that no reform of the law was necessary. And the final piece of advice assumes that anencephalics are to be kept alive at all costs, regardless of suffering and expense, until they eventually expire.

The Director of Public Prosecutions does not seem to have consulted any of the recognised representatives of the medical profession. His office has confirmed that the Daily Telegraph gave a correct report of the exclusive interview granted to the reporter. Those doctors who do not read the Daily Telegraph should therefore take note of what the Director of Public Prosecutions has said. We should also note that the Attorney General is considering referring the Arthur case to the Court of Criminal Appeal on a point of law arising out of the direction of the judge. ${ }^{5}$ Let us not also forget that in a recent case in which there were record damages of a quarter of a million pounds for severe brain damage sustained by a woman whose heart had stopped after an operation the Master of the Rolls (Lord Denning) observed that it was "a pity" that she had been resuscitated by the doctors. ${ }^{6}$

No one would claim that the law is clear on these issues. Nevertheless, until the present Director of Public Prosecutions decided to take an interest in them both the medical profession and patients felt confident that doctors following accepted medical procedures would not be prosecuted. If the Director of Public Prosecutions believes that public interest requires 